\title{
The Interaction of Fetuin with Phosphatidylcholine Monolayers
}

\section{CHARACTERIZATION OF A LIPOPROTEIN MEMBRANE SYSTEM SUITABLE FOR THE ATTACHMENT OF MYXOVIRUSES}

\author{
By J. M. TIFFANY AND H. A. BLOUGH \\ Department of Microbiology, School of Medicine, University of Pennsylvania, Philadelphia, Pa. \\ 19104, U.S.A.
}

(Received 22 October 1969)

\begin{abstract}
1. An artificial membrane system was formed by spreading at air/water and oil/water interfaces, by using phosphatidylcholine and the glycoprotein fetuin (mol.wt. 48400). 2. The plot of increase of interfacial pressure against amount of protein added beneath a monomolecular film of phosphatidylcholine showed two discontinuities, corresponding to the completion of two distinct layers of protein: (a) largely denatured and closely associated with the polar head groups of phosphatidylcholine, possibly with penetration of non-polar protein groups between the phosphatidylcholine molecules and $(b)$ an additional adsorbed layer of substantially native fetuin in either a close-packed or open-lattice array. A more compactly organized membrane was apparently formed at pH 7.4 with $1 \mathrm{mM}-\mathrm{Mg}^{2+}$ in the aqueous phase than without $\mathrm{Mg}^{2+}$; at $15 \mathrm{mM}-\mathrm{Mg}^{2+}$, more random adsorption of protein appeared to take place. Qualitatively similar results were obtained at pH5.1 with 1 mM- $\mathrm{Mg}^{2+}$. Closer initial packing of the phosphatidylcholine layer decreased both the magnitude of the interfacial pressure change and the amounts of protein bound in the two layers. 3. The amount of $N$-acetylneuraminic acid released by neuraminidase (EC 3.2.1.18) in the subphase was measured at pH 5.1; a mean distribution of $9.7 \times 10^{13}$ residues $/ \mathrm{cm}^{2}$ was calculated for the completed second protein layer.
\end{abstract}

Myxoviruses have surface projections or 'spikes' consisting in part of haemagglutinin. This binds specifically to sialic acid residues of surface glycoproteins of erythrocytes, causing bridging between cells and clumping. A similar process of attachment occurs as the first stage of infection of susceptible cells; it can be blocked temporarily by treatment of the cell surfaces with neuraminidase (the 'receptordestroying enzyme') (Burnet, 1948), which removes the specific attachment sites and releases sialic acid.* Investigations of the kinetics of myxovirus attachment and the function of surface components of the virus in this process have up to now involved the use of systems of natural cells or membranes (Henle, 1949; Hoyle, 1950; Cairns \& Fazekas de St Groth, 1957; Morgan \& Rose, 1968), which have a highly heterogeneous surface composition and largely unknown structure. No reproducible, defined artificial surface system for the study of viruses has hitherto been produced. In this paper we describe the formation and characterization of

* Sialic acid as used in this paper means $N$-acetylneuraminic acid. No other forms such as $N$-glycollylneuraminic acid were detected by g.l.c. (Craven \& Gehrke, 1968). such a system, consisting of layers of a glycoprotein stabilized by lipid.

Fetuin, a glycoprotein from foetal calf serum, contains 12-14 sialic acid residues per molecule (Spiro, 1960, 1962), all of which are terminal (Spiro, 1960). Blough (1965) showed by electron microscopy and Fazekas de St Groth \& Gottschalk (1963) showed by physicochemical methods that fetuin and other sialoglycoproteins attach to influenza virus at one or more points. Our aim was to produce an artificial membrane (or surface film) by spreading that would retain the character and sialic acid group distribution of the native fetuin. Eley \& Hedge $(1956,1957)$ have described a method of spreading a protein under a monomolecular film of lipid at an air/water interface to form a layer of native protein adsorbed to a denatured proteinlipid complex. Recent work by others (Colacicco, Rapport \& Shapiro, 1967; Camejo, Colacicco \& Rapport, 1968; Colacicco, 1969; Khaïat \& Miller, 1969; Quinn \& Dawson, 1969), on similar systems with a variety of lipids and proteins, has established many of the properties of such membranes.

We have investigated the structure of a triplelayered membrane of phosphatidylcholine and 
fetuin under differing degrees of compression of the phosphatidylcholine layer at air/water and oil/water interfaces, and the effect on it of variation of $\mathrm{Mg}^{2+}$ concentration and $\mathrm{pH}$. The techniques used were measurement of interfacial pressure and viscosity, and enzymic hydrolysis to estimate the distribution of sialic acid groups.

\section{MATERIALS AND METHODS}

All water was doubly distilled from alkaline $\mathrm{KMnO}_{4}$ in all-Pyrex apparatus to remove surface-active contaminants. The trough used for spreading experiments was of Teflon-coated aluminium and conical in shape (maximum diameter $15 \mathrm{~cm}$, included angle $90^{\circ}$ ) so that the area of the interface could be altered by withdrawal of subphase through the tip of the cone. The trough was thoroughly cleaned before each run; the liquid level was raised until the meniscus stood above the rim of the trough and any existing surface film was largely removed by sweeping with waxed glass strips. Any residual contamination was removed by extensive suction. Between fillings with buffer, the trough was washed with ethanol and ether, blown dry with clean air and rinsed with water. When experiments were done at the oil/water interface, light petroleum (b.p. $100-110^{\circ} \mathrm{C}$ ), sulphuric acid-washed and redistilled, was used as the upper phase. The whole apparatus was enclosed in a Plexiglas box for protection from dust and draughts.

Analytical-grade reagents were used in making up buffer solutions; the absence of surface-active contaminants in these was indicated by the constancy with time of the surface tension of swept solution interfaces. Buffer solutions used were $(a) 0.05 \mathrm{M}$-tris-HCl buffer, $\mathrm{pH} 7.4$, $+0.1 \mathrm{M}-\mathrm{NaCl}+0,1 \mathrm{~mm}-$ or $15 \mathrm{~mm}-\mathrm{MgCl}_{2} ;(b) 0.1 \mathrm{~m}$-citric acid-sodium citrate buffer, $\mathrm{pH} 5.1,+0.05 \mathrm{M}-\mathrm{NaCl}+1 \mathrm{~mm}-$ $\mathrm{MgCl}_{2}$. All measurements were made at $24 \pm 1^{\circ} \mathrm{C}$.

Phosphatidylcholine. Egg phosphatidylcholine was obtained from Mann Research Laboratories, Orangeburg, N.Y., U.S.A.; it was considered desirable to use a lipid of varied fatty acyl content since this might in part be responsible for strong binding of protein to the lipid film by permitting penetration of non-polar amino acid sidechains between adjacent lipid chains (Eley \& Hedge, 1957). T.l.c. indicated that the major component was phosphatidylcholine, with about $5 \%$ phosphatidylethanolamine and lysophosphatidylcholine. The major acyl components found by g.l.c. were: $\mathrm{C}_{16: 0}, 31.5 \%$; $\mathrm{C}_{16: 1}, 1 \% ; \mathrm{C}_{18: 0}, 17.1 \% ; \mathrm{C}_{18: 1}, 26.0 \% ; \mathrm{C}_{18: 2}, 14.9 \%$; $\mathrm{C}_{20: 0}, 1.5 \% ; \mathrm{C}_{20: 4}, 4.5 \%$. The mean molecular weight of phosphatidylcholine found from these results (used in calculations of areas/molecule in spread films) was 774 , the mean acyl chain length $C_{17.5}$ and the mean number of double bonds/chain 0.78 . For spreading at aqueous interfaces, phosphatidylcholine was dissolved in propan-2ol $(4 \mathrm{mg} / \mathrm{ml})$.

Fetuin. The glycoprotein fetuin was prepared from foetal calf serum by the method of Graham (1961); this preparation showed only a single precipitin line on immunoelectrophoresis against specific antibody (Blough, 1967). Its molecular weight was taken as 48400 (Spiro, 1960). For spreading, fetuin was dissolved in aq. $40 \%$ $(\mathrm{v} / \mathrm{v})$ propan-2-ol $(8 \mathrm{mg} / \mathrm{ml})$. Higher concentrations of propan-2-ol improve spreading but cause denaturation of fetuin (shown by turbidity) on standing. Only freshly made up solutions were used.

Neuraminidase. Clostridium perfringens neuraminidase (EC 3.2.1.18) was obtained from Worthington Biochemical Corporation, Freehold, N.J., U.S.A., at a minimum activity of 1.25 units $/ \mathrm{mg}$. One unit equals $1 \mu \mathrm{mol}$ of $N$-acetylneuraminic acid released/min from bovine submaxillary mucin $(1.6 \mathrm{mg}$ in $1 \mathrm{ml}$ of $0.1 \mathrm{M}$-sodium acetate buffer, pH 5.0, plus $4 \mu \mathrm{g}$ of enzyme) at $37^{\circ} \mathrm{C}$. This enzyme has no divalent cation requirement, and shows a sharp maximum in hydrolytic activity at $\mathrm{pH} 5.1$ with brain ganglioside (Burton, 1963), bovine sialyl-lactose or colominic acid (Cassidy, Jourdian \& Roseman, 1965) as substrate. The low level of phospholipase C activity in Burton's preparation (1963) was apparently removed by the chromatographic purification step in the extraction procedure of Cassidy et al. (1965), which was also followed by the supplier of the present material. No further assay of phospholipase activity was made.

Surface pressure measurements. Surface pressure was measured by the dipping-plate technique (Wilhelmy, 1863), by using a glass cover-slip suspended from a torsion balance. The plate was cleaned by soaking in chromic acid, followed by extensive washing in water to remove traces of metallic ions. After an initial reading on the clean surface, a calculated amount of phosphatidylcholine solution was added at the interface with a microlitre syringe, and the new torsion-balance reading was taken after adequate time for spreading and dispersion of the solvent (about $10 \mathrm{~min}$ ). Successive small amounts of the spreading solution of fetuin were injected just beneath the phosphatidylcholine film, and 15-30 min was allowed for equilibration of each additional amount of fetuin (or until there was no further change in surface pressure). The amounts of propan-2-ol introduced in the spreading solutions had no observable effect on surface pressure.

Surface viscosity measurements. The oscillating-needle method was used (Cumper \& Alexander, 1950). A logarithmic decrement of amplitude of oscillation can be determined for a needle suspended from a torsion wire and lying in the interface; the change in decrement observed when the needle oscillates in the interface in the presence of a surface layer is proportional to the drag exerted by this layer, and can be expressed as a surface viscosity. This was calculated from the expression (Fourt, 1939; Joly, 1964)

$$
\eta_{\mathrm{s}}=4 \times 2.303\left(\frac{\Delta}{\mathrm{T}}-\frac{\Delta_{0}}{\mathrm{~T}_{0}}\right) \frac{\mathrm{G}}{\mathrm{a}^{2}} \text { surface poise }
$$

where $\Delta$ and $\Delta_{0}$ are the logarithmic decrements (Joly, 1964) and $T$ and $T_{0}$ the torsional periods of the needle in the presence and absence of the film, respectively, $G$ the moment of inertia of the system and a the length of the needle. A gold-plated brass needle $3.6 \mathrm{~cm}$ long was used; the suspending fibre was $20 \mathrm{~cm}$ long and carried at its lower end, above the needle, a brass disc $7.6 \mathrm{~cm}$ in diameter and of mass $120.6 \mathrm{~g}$. The moment of inertia of the whole system, found from the variation in torsional period on adding an additional lead dise of known moment of inertia (Kalousek \& Vyšin, 1955), was $901.5 \mathrm{~g} \mathrm{~cm}^{2}$, and the torsional period in air was $4.699 \mathrm{~s}$. Since we are concerned here with the association between lipid and protein, the results given for surface viscosity are calculated from the 
decrement in the presence of the lipid film alone as reference point. The results plotted in Fig. 3 are therefore not expressed in 'absolute' surface poise. Swings were observed by an optical lever method, by using light reflected from a small mirror attached to the torsion bob, to a horizontal scale $1 \mathrm{~m}$ away. Readings of decrement were taken at each of the surface packings used for the surface tension measurements.

Sialic acid distribution in the surface film. Surface membranes with varying amounts of fetuin were spread on $49 \mathrm{ml}$ of $0.1 \mathrm{M}$-sodium citrate-citric acid buffer, pH5.1, in $15 \mathrm{~cm}$ Petri dishes. The phosphatidylcholine in all cases initially occupied $60 \AA^{2}$ /molecule. Sufficient fetuin in spreading solution was then injected under the phospha. tidylcholine layer to form the first fetuin layer, and additional amounts of fetuin were added under this to form the second layer in various stages of completion. After equilibration of the membrane, $1 \mathrm{ml}$ of neuraminidase $(0.1 \mathrm{mg} / \mathrm{ml}$ in sodium citrate-citric acid buffer) was added to the subphase, and the dishes were incubated at $37^{\circ} \mathrm{C}$ for $40 \mathrm{~h}$. Samples $(10 \mathrm{ml})$ were then withdrawn without disturbing the surface layer, freeze-dried and extracted twice with hot methanol to remove the sialic acid released by enzymic hydrolysis (Craven \& Gehrke, 1968). The sialic acid (minus most of the neuraminidase and salt) was determined by the fluorimetric method of Hess \& Rolde (1964), with $5 \mathrm{~mm}$-3,5-diaminobenzoic acid in $0.125 \mathrm{M}-\mathrm{HCl}$. The dried methanolic extracts were heated for $16 \mathrm{~h}$ at $100^{\circ} \mathrm{C}$ in screw-capped tubes with $0.4 \mathrm{ml}$ of reagent. A sample $(25 \mu \mathrm{l})$ was then added to $1 \mathrm{ml}$ of $0.05 \mathrm{M}-\mathrm{HCl}$ in the cell of an Eppendorf spectrofluorimeter, with a 405/436 nm combination primary filter and a 500-3000 nm secondary filter. Controls of neuraminidase $(10 \mathrm{ml}$ at $2 \mu \mathrm{g} / \mathrm{ml})$, salt $(10 \mathrm{ml}$ of the sodium citrate-citric acid buffer), fetuin $(100 \mu \mathrm{g})$ and sialic acid-free fetuin $(100 \mu \mathrm{g})$ were run concurrently. Sialic acid-free fetuin was produced by mild hydrolysis of fetuin with $12.5 \mathrm{~mm}$-sulphuric acid for $1 \mathrm{~h}$ at $80^{\circ} \mathrm{C}$ (Spiro, 1960). The amounts of neuraminidase and salt are the same as in the samples withdrawn from the subphase for assay of liberated sialic acid; the amounts of fetuin and sialic acid-free fetuin are slightly greater than the total amount of fetuin used per dish in forming the membrane. Background values of free sialic acid in these controls (to be subtracted from the amounts of enzymically released sialic acid) were together less than $10 \%$ of the amount enzymically released from the completed mem. brane. A 90-95\% recovery of sialic acid in the methanol extraction step was achieved in control experiments with 1-100 $\mu \mathrm{g}$ of sialic acid.

\section{RESULTS}

Surface-pressure measurements. Forco-area curves for monolayers of phosphatidylcholine at air/water and oil/water interfaces are shown in Fig. 1. An area of $40 \AA^{2} /$ molecule close to the collapse point is lower than reported elsewhere for partially-unsaturated phosphatidylcholine monolayers (Demel, van Deenen \& Pethica, 1967), or for egg phosphatidylcholine (de Bernard, 1958). However, the acyl composition given above differs from that of egg phosphatidylcholine reported by other workers (e.g. Dyatlovitskaya, Volkova \& Bergel'son, 1967)

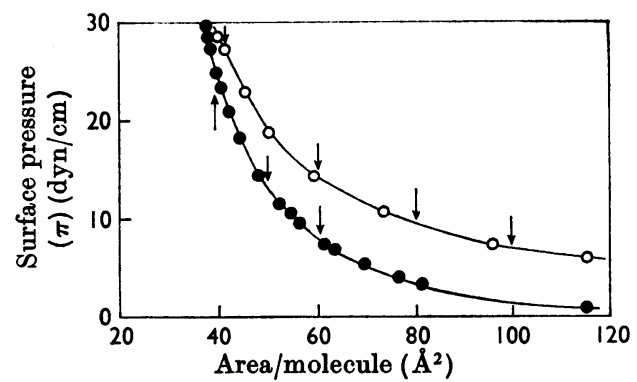

Fig. 1. Force-area curves for phosphatidylcholine at the air/water (๑) and oil/water (O) interfaces using $0.05 \mathrm{M}$ tris-HCl buffer, pH 7.4. Arrows indicate the areas $/$ molecule used in protein/lipid spreading experiments : air/water $40,50,60 \AA^{2} /$ molecule; oil/water, $40,60,80,100 \AA^{2} /$ molecule.

in having an appreciably higher $\mathrm{C}_{18: 0}$ and lower $\mathrm{C}_{18: 1}$ content; its monolayer spreading behaviour, therefore, more closely approaches that of a fullysaturated phosphatidylcholine. The small phosphatidylethanolamine content noted above may also influence this to some extent.

Surface-pressure results for the lipid/protein system are plotted (Fig. 2) in the form of the increase in surface pressure, $\Delta \pi$ (above the initial pressure of the phosphatidylcholine film), against the protein/lipid molar ratio in the membrane. The curves show the same general form as those described by Eley \& Hedge (1956) for a number of proteins, but differ in the magnitude of $\Delta \pi$ and in the molar ratios at which the discontinuities occur (Table 1). Only a very slow rate of rise of $\Delta \pi$ was found above the second discontinuity, and no further discontinuities were found at very high molar ratios.

Effect of initial area/phosphatidylcholine molecule. Phosphatidylcholine was spread at initial areas of 60,50 and $40 \AA^{2} /$ molecule at the air/water interface (surface pressures of $8,12.5$ and $28 \mathrm{dyn} / \mathrm{cm}$ respectively), and $100,80,60$ and $40 \AA^{2} /$ molecule at the oil/water interface $(7,10,14.3$ and $28.9 \mathrm{dyn} / \mathrm{cm}$ respectively). In agreement with the results of others (Colacicco et al. 1967, Khaïat \& Miller, 1969; Quinn \& Dawson, 1969), the magnitude of $\Delta \pi$ falls with higher initial surface pressures. Within the range of pressures studied, however, two discontinuities were always apparent, although the first occurred at very low surface concentrations of fetuin. This may indicate that at a sufficiently high surface pressure, the first layer of protein would be altogether absent (Khaïat \& Miller, 1969; Quinn \& Dawson, 1969). At the oil/water interface, where cohesive forces between the hydrocarbon chains of phosphatidylcholine are largely removed, the amount of protein in the first layer is generally 


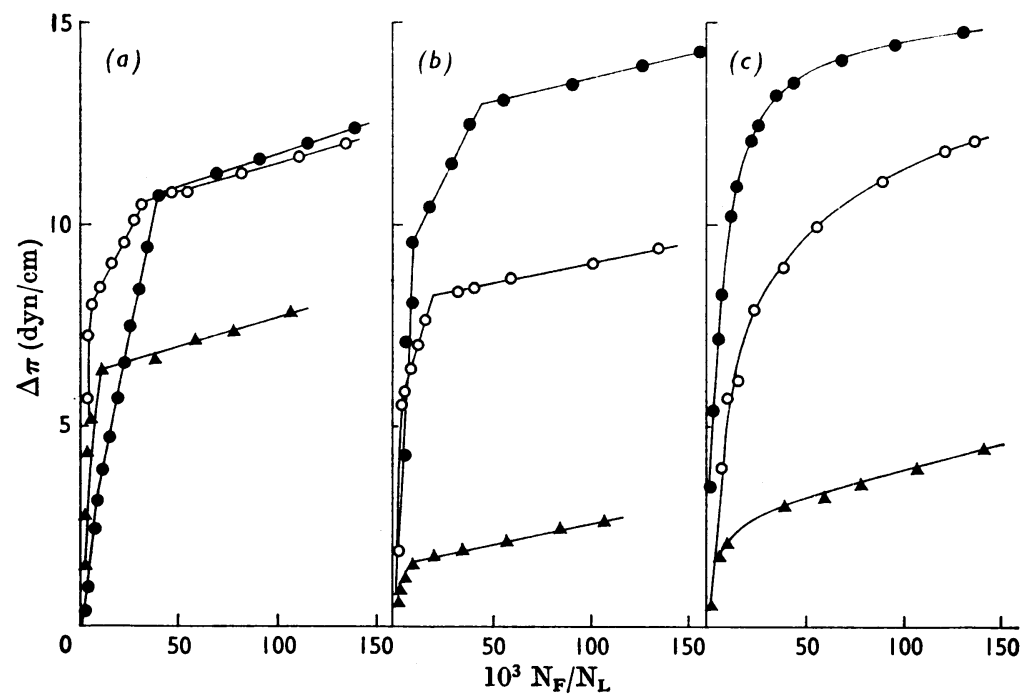

Fig. 2. Change in surface pressure with addition of fetuin under a phosphatidylcholine monolayer at the air/ water interface on $0.05 \mathrm{M}$-tris-HCl buffer, $\mathrm{pH}$ 7.4. Initial areas/molecule of phosphatidylcholine are: $60 \AA^{2}$ (๑); $50 \AA^{2}(O) ; 40 \AA^{2}(\Delta)$. The concentration of $\mathrm{Mg}^{2+}$ in the buffer is: $a, 0 ; b, 1 \mathrm{mM} ; c, 15 \mathrm{mM}$. $\mathrm{N}_{\mathrm{L}}$ is fixed by the initial area/phosphatidylcholine molecule. The molar ratio $\mathrm{N}_{F} / \mathrm{N}_{L}$ for a given initial phosphatidylcholine area is proportional to the amount of protein present.

Table 1. Fetuin/phosphatidylcholine molar ratio in the first and second fetuin layers, and area/fetuin molecule in the second layer

Molar ratios $\left(\mathrm{N}_{\mathrm{F}} / \mathrm{N}_{\mathrm{L}}\right)$ for the first layer are the values at which the first discontinuity occurs in the plot of increase in surface pressure $(\Delta \pi)$ against molar ratio. Values for the second layer are the difference between the ratios at the first and second discontinuities. $N_{L}$ is fixed by the initial area/molecule of phosphatidylcholine in the spread monolayer. All determinations at $\mathrm{pH} 7.4$ were on $0.05 \mathrm{~m}$-tris-HCl buffer, and at pH5.1 on 0.1 M-sodium citrate-citric acid buffer.

\begin{tabular}{|c|c|c|c|c|c|c|}
\hline \multirow[b]{2}{*}{ Interface } & \multirow[b]{2}{*}{$\mathrm{pH}$} & \multirow{2}{*}{$\begin{array}{c}\text { Concn. of } \mathrm{Mg}^{2+} \\
\mathrm{mM}\end{array}$} & \multirow{2}{*}{$\begin{array}{l}\text { Phosphatidylcholine } \\
\text { area ( } \AA^{2} / \text { molecule) }\end{array}$} & \multicolumn{2}{|c|}{$10^{3} \mathrm{~N}_{\mathrm{F}} / \mathrm{N}_{\mathrm{L}}$} & \multirow{2}{*}{$\begin{array}{l}\text { Area of fetuin } \\
\text { in second layer } \\
\left(\AA^{2} / \text { molecule }\right)\end{array}$} \\
\hline & & & & lst layer & 2nd layer & \\
\hline \multirow[t]{8}{*}{ Air/water } & 7.4 & 0 & $\begin{array}{l}60 \\
50\end{array}$ & $\begin{array}{r}12.3 \\
7.1\end{array}$ & $\begin{array}{l}28.0 \\
24.9\end{array}$ & $\begin{array}{l}2140 \\
2010\end{array}$ \\
\hline & & & 40 & 5.1 & 17.0 & 2350 \\
\hline & 7.4 & 1 & 60 & 11.9 & 33.1 & 1810 \\
\hline & & & 50 & 4.9 & 13.9 & 3580 \\
\hline & & & 40 & 0.6 & 8.0 & 5000 \\
\hline & 5.1 & 1 & 60 & 12.4 & 143.0 & 420 \\
\hline & & & 50 & 5.4 & 43.4 & 1150 \\
\hline & & & 40 & 2.6 & 43.9 & 910 \\
\hline \multirow[t]{8}{*}{ Oil/water } & 7.4 & 0 & 100 & 11.0 & 92.5 & 1080 \\
\hline & & & 80 & 23.5 & 62.8 & 1270 \\
\hline & & & 60 & 13.3 & 78.1 & 770 \\
\hline & & & 40 & 3.5 & 23.0 & 1740 \\
\hline & 7.4 & 1 & 100 & 22.4 & 94.6 & 1060 \\
\hline & & & 80 & 15.5 & 83.5 & 960 \\
\hline & & & 60 & 13.6 & 54.9 & 1090 \\
\hline & & & 40 & 6.2 & 42.3 & 6450 \\
\hline
\end{tabular}

higher than at the air/water interface with a comparable initial surface pressure. This suggests that penetration of the hydrocarbon region by the protein may be of greater importance in stabilizing the first layer than ionic interaction with ionic groups of the lipid, as has been suggested by Colacicco 
et al. (1967), since there are in this case fewer polar groups present at the oil/water than the air/water interface.

Effect of $\mathbf{M g}^{2+}$ concentration. $\mathrm{Mg}^{2+}$ concentrations of 0,1 and $15 \mathrm{~mm}$ were chosen as representing very roughly the 'low', 'normal' and 'high' ranges commonly used in biological investigations. Very little difference was seen between the form of the $\Delta \pi$ curves for zero and $1 \mathrm{~mm}-\mathrm{Mg}^{2+}$. We may note, however, that at the air/water interface the area/ fetuin molecule in the second layer rises as the amount of fetuin in the first layer falls when $1 \mathrm{~mm}$ $\mathrm{Mg}^{2+}$ is present; in the absence of $\mathbf{M g}^{2+}$, this area remains essentially constant (Table 1 ). The effect of $1 \mathrm{~mm}-\mathrm{Mg}^{2+}$ therefore appears to be a closer relationship between the amounts of protein in the first and second layers. The more marked decrease in the amount of protein bound in the first layer at 40 and $50 \AA^{2} /$ molecule of phosphatidylcholine may be related to the ionic binding of $\mathrm{Mg}^{2+}$ to the polar groups of phosphatidylcholine (demonstrated by Shah \& Schulman, 1967, for $\mathrm{Ca}^{2+}$ ). At the oil/water interface both these effects are less evident. At $15 \mathrm{~mm}-\mathrm{Mg}^{2+}$ thediscontinuous form of curveis not seen; instead, a smooth curve reminiscent of a Langmuir adsorption isotherm is found. Hence no discontinuity values appear in Table 1 for this magnesium concentration.

Effect of pH. Fetuin was spread at the air/water interface under phosphatidylcholine monolayers at 60,50 and $40 \AA^{2} /$ molecule on citrate buffer at pH5.1 and $1 \mathrm{~mm}-\mathrm{Mg}^{2+}$. The curves follow the regular Eley \& Hedge (1956) form, but show considerable differences in the molar ratios required to complete the second protein layer (Table 1) from those at pH 7.4. The area/molecule of fetuin adsorbed in the second layer is much lower at pH 5.1 than at pH 7.4; there is, however, no indication of multilayer formation at the lower $\mathrm{pH}$ value, since the area/molecule is reasonably consistent with the estimate by Blough (1965) for the dimensions of the fetuin molecule.

Surface viscosity measurements. At the air/water interface at pH 7.4, qualitatively similar results were obtained of viscosity as a function of protein/ lipid molar ratio at $\mathrm{Mg}^{2+}$ concentrations of 0,1 and $15 \mathrm{~mm}$. A steep initial rise of viscosity was noted, reaching a peak in the region of completion of the first protein layer. The viscosity then decreased to a wide minimum in the region of completion of the second layer. A further, more gradual rise occurred at higher molar ratios. Fig. 3 shows the curves for initial areas of 60,50 and $40 \AA^{2} /$ phosphatidylcholine molecule at $1 \mathrm{~mm}-\mathrm{Mg}^{2+}$. At both 0 and $15 \mathrm{~mm}-\mathrm{Mg}^{2+}$, the curves, though substantially similar in shape, showed rather lower viscosities and much greater scatter of points than at $1 \mathrm{~mm}-\mathrm{Mg}^{2+}$. The organization of the membrane therefore appears to be

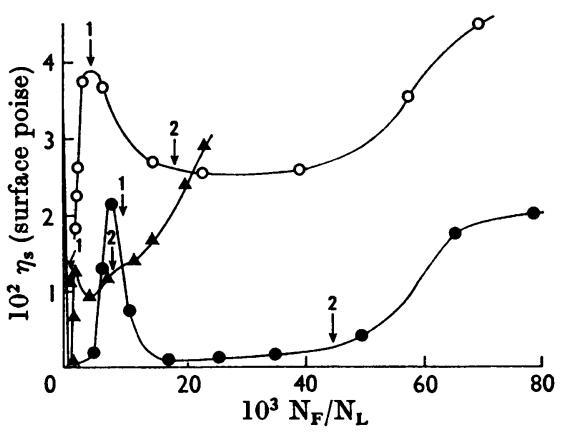

Fig. 3. Surface viscosity of phosphatidylcholine-fetuin films at the air/water interface on $0.05 \mathrm{M}$-tris-HCl buffer, $\mathrm{pH} 7.4$, at $1 \mathrm{~mm}-\mathrm{Mg}^{2+}$, measured with the oscillatingneedle viscometer. Initial areas per molecule of phosphatidylcholine are: $60 \AA^{2}(0) ; 50 \AA^{2}(0) ; 40 \AA^{2}(\Delta)$. Arrows indicate the values of molar ratio $\left(\mathrm{N}_{F} / \mathrm{N}_{L}\right)$ of protein added to lipid present that correspond to the completion of the first and second layers of protein (from Table 1). Viscosity is calculated relative to an arbitrary zero when only a lipid monolayer is present.

improved at a $\mathrm{Mg}^{2+}$ concentration of $1 \mathrm{~mm}$. Measurements were not made at different $\mathrm{pH}$ values or at the oil/water interface.

Sialic acid distribution. Membranes were spread at $\mathrm{pH} 5.1$ and $1 \mathrm{~mm}-\mathrm{Mg}^{2+}$ with various amounts of protein from one complete layer to two complete layers. No further change in surface pressure was noted after addition of neuraminidase; although surface pressure changes cannot generally be used as a quantitative measure of protein adsorption (Khaïat \& Miller, 1969; Quinn \& Dawson, 1969), and hence attachment of neuraminidase to the membrane is not detectable, it seems probable that direct displacement of fetuin by neuraminidase would affect $\Delta \pi$. Wo therefore feel that the membrane retains its structure even in the presence of the enzyme. In addition, the presence of unadsorbed fetuin in the subphase was investigated by measuring the amount of sialic acid released by hydrolysis from a sample of the subphase after formation of a membrane, in the absence of enzyme. The subphase in the Petri dish was stirred by a small Teflon-coated magnetic spinbar at about $50 \mathrm{rev} . / \mathrm{min}$ to avoid formation of a stagnant layer close to the membrane. Samples $(10 \mathrm{ml})$ were withdrawn from a total subphase volume of $50 \mathrm{ml}$, from about the midpoint of depth of the dish. Neuraminidase solution $(0.2 \mathrm{ml} ; 0.1 \mathrm{mg} / \mathrm{ml})$ was added and the samples were incubated for $16 \mathrm{~h}$ at $37^{\circ} \mathrm{C}$. The sialic acid released was then extracted with methanol as described above and was assayed either by the method of Hess \& Rolde (1964) or by the g.l.c. method of Craven \& Gehrke (1968). No free sialic acid was detected by either of these methods; in our hands 


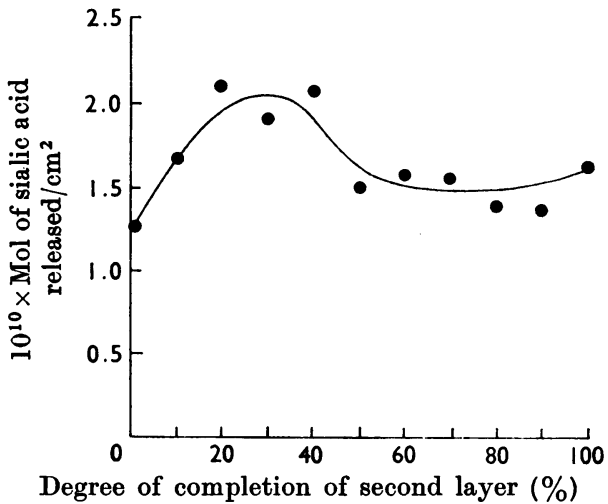

Fig. 4. Amount of sialic acid released by neuraminidase from fetuin in phosphatidylcholine-fetuin films, at various degrees of completion of the second protein layer. Air/water interface on $0.1 \mathrm{M}$-citrate buffer, pH5.1, $1 \mathrm{~mm}$ $\mathrm{Mg}^{2+}$. No. of mol of sialic acid was calculated by using mol.wt. 309 for $N$-acetylneuraminic acid.

the limits of detection by these methods are about $20 \mathrm{ng}$ and $10 \mathrm{ng}$ respectively. Similar investigations on fetuin adsorbed at the air/water interface in the absence of a lipid film were not performed. Results of the amount of sialic acid released $/ \mathrm{cm}^{2}$ as a function of the degree of completion of the second protein layer are shown in Fig. 4, the values being $1.25 \pm 0.21 \times 10^{-10} \mathrm{~mol} / \mathrm{cm}^{2}$ in the first layer and $1.62 \pm 0.36 \times 10^{-10} \mathrm{~mol} / \mathrm{cm}^{2}$ in the second layer (mean \pm S.D., ten determinations for each value). These correspond to $7.5 \times 10^{13}$ and $9.7 \times 10^{13}$ residues $/ \mathrm{cm}^{2}$ respectively. The high scatter in these values of sialic acid determined is probably introduced by variations in the degree of regularity of spreading by the protein, and hence the accessibility of sialic acid groups to the enzyme. Acid hydrolysis of fetuin indicated that sialic acid comprised $7.9 \%$ of the molecule, agreeing fairly well with the values of $8.2 \%$ found by Spiro \& Spiro (1962) and 8.4\% by Oshiro \& Eylar (1968). Neuraminidase treatment of fetuin in solution gave $7.6 \%$, indicating that $96 \%$ of the sialic acid content can be removed by enzymic hydrolysis.

\section{DISCUSSION}

The surface-pressure results for the spreading of fetuin under phosphatidylcholine monolayers at various initial packings and at 0 or $1 \mathrm{~mm}-\mathrm{Mg}^{2+}$ concentration support Eley \& Hedge's (1956) interpretation of the structure of the interfacial complex, although Table 1 shows that there is ennsiderable variation in the amount of protein bound at a given phosphatidylcholine packing; this may be related to binding of $\mathrm{Mg}^{2+}$ by phosphatidyl- choline or protein. It is also possible that denaturation is not always complete in the first layer, and may also occur to some extent in the second layer. The fetuin molecule consists of a single polypeptide strand, but contains six disulphide bonds (Spiro \& Spiro, 1962); it may therefore be incapable of complete denaturation under these spreading conditions. Eley \& Hedge (1956), Colacicco et al. (1967) and Quinn \& Dawson (1969) all suggest that the initial interaction is through ionic bonding between phosphatidylcholine and anionic groups of the protein. However Colacicco et al. do not consider likely the additional stabilization by penetration of non-polar amino acid side chains between acyl chains of the phosphatidylcholine layer. These authors suggest that a major part of the increase in surface pressure (corresponding to a release of surface free energy) may be due to re-ordering of water solvating these charged groups, which is released in the process of ion-pairing. Quinn \& Dawson (1969) conclude, however, from measurement of the increase in surface radioactivity, by using a labelled protein, that penetration does occur, but is not so extensive as to indicate the formation of a mixed monolayer of lipid and protein. The high carbohy. drate content of fetuin (Spiro, 1960) may also be important in promoting an ordered water structure. In the second layer, a similar effect, as the array of native molecules is built up and stabilized by specific polar interactions with the first layer, in addition to lateral repulsion between the ionic groups of adjacent protein molecules, would give an additional surface pressure rise. Above the completion of the second layer, random binding of native protein (lacking the ordering effect of the denatured layer) may give a further small rise in pressure by some re-ordering of the existing layers; ionic repulsion between randomly adsorbed molecules would also increase surface pressure slightly. It is conceivable that after addition of very large amounts of protein, the amount of propan-2-ol introduced into the subphase from the spreading solution influences $\Delta \pi$ to a small extent. At $15 \mathrm{~mm}-\mathrm{Mg}^{2+}$, the presence of the divalent cation may permit a greater variety of adhesive contacts of the native molecules, possibly through sialic acid groups on the protein surface, so that random multilayer adsorption takes place. Camejo et al. (1968) present evidence that protein adsorption follows a Langmuir type of relationship between amount of protein adsorbed and bulk concentration. However, we have no evidence for equilibration of spread protein between the interface and the bulk phase (at least up to the completion of the second protein layer), as indicated by our failure to detect hydrolysable sialic acid in the subphase. The influence of high $\mathrm{Mg}^{2+}$ concentration is probably limited to an obscuring of the sharp discontinuities in the $\Delta \pi$ curves. At the oil/ 
water interface, the effect of $1 \mathrm{~mm}-\mathrm{Mg}^{2+}$ is not readily determinable from the data available.

The effect of a decrease in $\mathrm{pH}$ of the subphase from 7.4 to 5.1 was a considerable fall in the area occupied/fetuin molecule in the second layer, from 1810 to $420 \AA^{2} /$ molecule, at $60 \AA^{2} / \mathrm{molecule}$ of phosphatidylcholine. As mentioned above, this probably indicates formation of a well-ordered layer at pH 5.1. Blough (1965) gives the dimensions of the fetuin molecule by electron microscopy as a sphere of diameter $25 \AA$, or an elongated form with mean dimensions of $42 \AA \times 15 \AA$ (at about $\mathrm{pH}$ 6.5). Titration data given by Spiro (1960) for fetuin indicate an appreciable difference in charge over the $\mathrm{pH}$ range 5.1 to 7.4 ; it is thus possible that at pH 5.1, which is closer to its isoelectric point of pH 3.3 (Spiro, 1960) and where the charge on the molecule is therefore less, fetuin will be able to occupy $420 \AA^{2} /$ molecule in a well-ordered twodimensional array (Khaïat \& Miller, 1969). At pH 7.4, on the other hand, the charge is greater and the molecule occupies a greater area. It is not clear whether the area of $1810 \AA^{2} /$ molecule at $\mathrm{pH} 7.4$ is solely the result of an overall size change and increased intermolecular repulsion; the change in configuration may involve a considerable elongation of the molecule into a rodlike form capable of forming a fairly regular lattice where each molecule accounts for an area much larger than that delineated by its physical dimensions. This elongation could conceivably be produced as a form of reversible denaturation on contact with the first protein layer of the membrane; electron-microscopic observations have been made of filamentous molecules of fetuin attached to the surface projections of myxoviruses (H. A. Blough, unpublished work).

The viscosity data also reinforce the basic interpretation of Eley \& Hedge (1956). The viscosity of the membrane rises with attachment of denatured protein chains as a network of inter- and intramolecular lateral interactions is built up, to a maximum at the completion of this first layer. The altered ionic environment, including lateral ionic repulsive forces, in the presence of second-layer protein molecules causes a decrease in viscosity to a minimum at about the completion of the second layer. The further large rise in viscosity is not easily explained, although a number of possible contributory factors must beconsidered : $(a)$ bridging between second-layer molecules by additional randomly adsorbed fetuin molecules; (b) release of fetuin into solution above the region of completion of the second layer, increasing the viscosity of the subphase and hence $\Delta_{0}$ in Fourt's (1939) expression; (c) the inapplicability of Fourt's expression to very thick multilayered structures and $(d)$ cumulative effects of propan-2-ol from spreading solutions. At $15 \mathrm{~mm}$ -
$\mathrm{Mg}^{2+}$, viscosity of the membrane was less than at lower $\mathrm{Mg}^{2+}$ concentrations, and showed much less marked maxima and minima. The forces between randomly adsorbed protein molecules may hence be relatively weak and the loose structure easily shared.

It was expected that the amount of sialic acid released from the first protein layer would differ from that released from the second layer. All sialic acid groups present in the denatured molecule are probably fully exposed and any not directly involved in binding to polar groups of the lipid are directed towards the aqueous phase. As this layer becomes progressively covered with native protein, the number of available groups changes. At low second-layer coverages, there will be contributions to the measured distribution from $(a)$ uncovered regions of the first layer, $(b)$ the regions of the native molecule that will be exposed in the completed second layer, and (c) the 'sides' of the second layer molecules, which will be concealed when the layer is completed. Access to (a) and (c) will depend on the degree of coverage of the first layer by second-layer molecules and on the size of the neuraminidase molecule relative to fetuin. No information is currently available on the molecular weight or dimensions of $C$. perfringens neuraminidase. At second-layer coverages above about 30\%, sialic acid groups in regions $(a)$ and $(c)$ would probably not be accessible to a large enzyme molecule. The rapid fall in amount of sialic acid released above about $30 \%$ coverage, and its rise towards $100 \%$ coverage, suggests such steric hindrance; when the enzyme molecule is prevented from reaching sialic acid groups in regions $(a)$ and $(c)$, only those in region $(b)$, rising to a maximum at $100 \%$ coverage, can contribute to the total. If we assume that in the complete second layer at pH 5.1 we have uniform arrays both of native fetuin molecules and of sialic acid groups on the exposed surfaces of these molecules, the mean separation of sialic acid groups (in a hexagonal array) is approximately $11 \AA$. This figure seems a little large if we are to account for a mean value of 13.6 residues/molecule (Spiro, 1960); some of these may be buried within the molecule, as suggested by Oshiro and Eylar (1969).

The membrane system described is readily formed to any desired size (about $176 \mathrm{~cm}^{2}$ in the apparatus mentioned above).

This work was conducted under the sponsorship of the Commission on Influenza, Armed Forces Epidemiological Board, and was supported by the U.S. Army Medical Research and Development Command, Department of the Army (Research Contract no. DADA-17-67C-7128) and grants from the American Thoracic Society and Damon Runyon Memorial Fund for Cancer Research (DRG-948A). J.M.T. is a Damon Runyon Memorial Fund Research Fellow. 


\section{REFERENCES}

Blough, H. A. (1965). Biochem. J. 96, 34 P.

Blough, H. A. (1967). Virology, 31, 514.

Burnet, F. M. (1948). Lancet, i, 7.

Burton, R. M. (1963). J. Neurochem. 10, 503.

Cairns, H. J. F. \& Fazekas de St Groth, S. (1957). J. Immun. 78, 191.

Camejo, G., Colacicco, G. \& Rapport, M. M. (1968). J. Lipid Res. 9, 562.

Cassidy, J. T., Jourdian, G. W. \& Roseman, S. (1965). J. biol. Chem. 240, 3501.

Colacicco, G. (1969). J. Colloid \& Interface Sci. 29, 345.

Colacicco, G., Rapport, M. M. \& Shapiro, D. (1967). J. Colloid \& Interface Sci. 25, 5.

Craven, D. A. \& Gehrke, C. W. (1968). J. Chromat. 37, 414.

Cumper, C. W. N. \& Alexander, A. E. (1950). Trans. Faraday Soc. 46, 235.

de Bernard, L. (1958). Bull. Soc. Chim. biol. 40, 161.

Demel, R. A., van Deenen, L. L. M. \& Pethica, B. A. (1967). Biochim. biophys. Acta, 135, 11.

Dyatlovitskaya, E. V., Volkova, V. I. \& Bergel'son, L. D. (1967). Biokhimiya, 32, 1227.

Eley, D. D. \& Hedge, D. G. (1956). J. Colloid Sci. 11, 445.

Eley, D. D. \& Hedge, D, G. (1957). J. Colloid Sci. 12, 419.

Fazekas, de St Groth, S. \& Gottschalk, A. (1963). Biochim. biophys. Acta, 78, 248.
Fourt, L. G. (1939). J. phys. Chem. 43, 887.

Graham, E. R. B. (1961). Aust. J. Sci. 24, 140.

Henle, W. (1949). J. exp. Med. 90, 1.

Hess, H. H. \& Rolde, E. (1964). J. biol. Chem. 239, 3215.

Hoyle, L. (1950). J. Hyg., Camb., 48, 277.

Joly, M. (1964). In Recent Progress in Surface Science, vol. 1, pp. 4, 5. Ed. by Danielli, J. F., Pankhurst, K. G. A. \& Riddiford, A. C. New York: Academic Press Inc.

Kalousek, M. \& Vyšin, V. (1955). Coll. Czech. chem. Commun. 20, 777.

Khaĩat, A. \& Miller, I. R. (1969). Biochim. biophys. Acta, 183, 309.

Morgan, C. \& Rose, H. M. (1968). J. Virol. $2,925$.

Oshiro, Y. \& Eylar, E. H. (1968). Archs Biochem. Biophys. $127,476$.

Oshiro, Y. \& Eylar, E. H. (1969). Archs. Biochem. Biophys. 130, 227.

Quinn, P. J. \& Dawson, R. M. C. (1969). Biochem.J. 113, 791.

Shah, D. O. \& Schulman, J. H. (1967). J. Lipid Res. 8, 227.

Spiro, R. G. (1960). J. biol. Chem. 235, 2860.

Spiro, R. G. (1962). J. biol. Chem. 237, 382.

Spiro, R. G. \& Spiro, M. J. (1962). J. biol. Chem. 237, 1507.

Wilhelmy, H. (1863). Annln Phys. 119, 177. 